Article

\title{
Muscle Fitness to Visceral Fat Ratio, Metabolic Syndrome and Ideal Cardiovascular Health Metrics
}

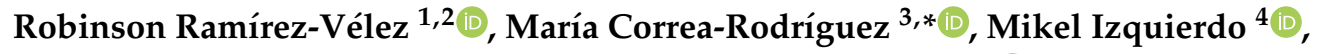 \\ Jacqueline Schmidt-RioValle ${ }^{3}$ and Emilio González-Jiménez ${ }^{3}$ (1) \\ 1 Centro de Estudios para la Medición de la Actividad Física CEMA, Escuela de Medicina y Ciencias de la \\ Salud, Universidad del Rosario, Bogotá 111221, Colombia; robin640@hotmail.com \\ 2 GICAEDS Group, Faculty of Physical Culture, Sport and Recreation, Universidad Santo Tomás, \\ Bogotá 110311, Colombia \\ 3 Departamento de Enfermería, Facultad de Ciencias de la Salud, Avda. De la Ilustración, 60, \\ University of Granada, Granada 18016, Spain; jschmidt@ugr.es (J.S.-R.); emigoji@ugr.es (E.G.-J.) \\ 4 Department of Health Sciences, Public University of Navarre, Navarrabiomed, IdiSNA, CIBER de Fragilidad \\ y Envejecimiento Saludable (CB16/10/00315), Navarre 31006, Spain; mikel.izquierdo@gmail.com \\ * Correspondence: macoro@ugr.es; Tel.: +34-95-8243498; Fax: +34-95-8242894
}

Received: 5 December 2018; Accepted: 20 December 2018; Published: 22 December 2018

\begin{abstract}
This study aimed to investigate the association between the muscle fitness to visceral fat level (MVF) ratio and the prevalence of metabolic syndrome (MetS) and ideal cardiovascular health $(\mathrm{CVH})$ metrics among college students. A total of 1467 young adults recruited from the FUPRECOL study (Asociación de la Fuerza Prensil con Manifestaciones Tempranas de Riesgo Cardiovascular en Jóvenes y Adultos Colombianos), were categorized into four quartiles based on their MVF ratio. Muscular fitness was assessed using a digital handgrip dynamometer and visceral fat level was determined through bioelectrical impedance analysis. Ideal CVH was assessed, including lifestyle characteristics, anthropometry, blood pressure, and biochemical parameters. The body weight, waist circumference, body mass index (BMI), fat mass, fat mass index, and visceral fat level were significantly higher in subjects in Q1 (lower MVF ratio) than those in Q2, Q3, or Q4 $(p<0.001)$. The muscle fitness (handgrip and normalized grip strength (NGS)) of the subjects in Q4 was significantly greater than that of those in Q1 to Q2 $(p<0.001)$. Subjects with a medium-high MVF ratio (i.e., 3-4th quartiles) had an odds ratio of 2.103 of ideal CVH metrics after adjusting for age, gender, university, and alcohol intake ( $95 \%$ confidence interval (CI) 1.832 to $2.414 ; p<0.001$ ). A lower MVF ratio is associated with worse CVH metrics and a higher prevalence of MetS in early adulthood, supporting the hypothesis that the MVF ratio could be used as a complementary screening tool that could help clinicians identify young adults with unfavorable levels of $\mathrm{CVH}$ and metabolic risk.
\end{abstract}

Keywords: metabolic syndrome; muscle strength; visceral fat; ideal cardiovascular health; young adults

\section{Introduction}

Abdominal adiposity, dyslipidemia, elevated blood pressure (BP), and impaired fasting glycemia have been identified as cardiometabolic risk factors associated with cardiovascular disease (CVD), with the fastest rise being seen in Latin-American countries [1]. In Colombia, Westernized dietary habits and chronic physical inactivity have been proposed as major factors involved in national overweight and obesity trends [2]. For example, in 2010, 51.2\% of women and men aged 18-64 years were either overweight or obese [3]. Excess weight was more prevalent in women than men (55.2\% versus $45.6 \%$ ), particularly concerning the obese subgroup (20.1\% versus $11.5 \%)$. 
Research assessing CVD risk in college students aged 18-24 has revealed an alarmingly high prevalence of abnormal risk factor profiles [4]. As many as 33\% of young adults are overweight [5], and this excess weight leads to dyslipidemia and increased incidence of metabolic syndrome (MetS) [6] as well as the risk of developing CVD [7]. In addition, excess epicardial adipose tissue has been proposed as a reliable marker of cardiovascular risk since it is associated with insulin resistance, MetS or fatty liver disease [8]. Taking into account that $80 \%$ of CVD events are preventable through diet and lifestyle, early detection and intervention are of special interest [9]. Due to the increasing burden of CVD, the American Heart Association (AHA) established the 2020 Strategic Impact Goals to define the concept of ideal cardiovascular health $(\mathrm{CVH})$ as well as the metrics needed to monitor this across populations [10]. The 7 metrics for assessing CVH in adults (age $\geq 20$ ) comprise 4 health behavior markers (current smoking, body mass index, physical activity, and healthy diet score) and 3 physiological health factors (total cholesterol, blood pressure, and fasting plasma glucose levels).

Very few studies have analyzed this ideal $\mathrm{CVH}$ in young adults, but these suggest a direct association with markers related to future cardiovascular events such as carotid intima-media thickness [11] or left ventricular structure and function later in life [12]. Similarly, Hruskova et al. demonstrated for the first time that $\mathrm{CVH}$ is associated with epicardial adipose tissue [13]. In line with this, muscle fitness has been identified as a predictor of cardiometabolic diseases and mortality [14,15]. The physiological mechanisms underlying the relationship between muscle fitness and cardiometabolic risk are fully understood, but muscle mass has been proposed as the main driver of their relationship, as skeletal muscle is the principal site of insulin-mediated glucose uptake, and this is closely related with muscle fitness [16]. Moreover, although low muscle fitness has been associated with CVD risk, studies assessing the independent role of the other components of fitness considered these to be confounders and therefore factors to be controlled in multivariate models $[17,18]$.

Poor diet, obesity, and low physical fitness levels have been shown to be the leading CVD risk factors in Colombian adults, raising concerns about whether an increase in the risk level of these conditions also affects cardiometabolic status $[19,20]$. These changes have resulted in an increase in the prevalence of overweight and obesity in Colombians, particularly young adults [21]. Additionally, the prevalence of ideal $\mathrm{CVH}$ has not been examined in any Latin-American college student population. It is very important to identify the risk factors and take steps to control non-communicable diseases in Colombia.

Low muscle fitness and high levels of visceral fat tissue have separately been shown to increase the risk of metabolic disorders and CVD early in life [17,22]. However, the potential influence of muscle fitness and visceral fat level together has not been investigated. Therefore, the aim of the present study was to evaluate the association of reduced grip strength (normalized grip strength) as a proxy measure for muscle fitness and physical health and increased visceral fat level mass ratio and the prevalence of MetS and ideal CVH metrics among college students.

\section{Methods}

\subsection{Participants and Study Design}

This was a secondary analysis of cross-sectional of data from the FUPRECOL study (Asociación de la Fuerza Prensil con Manifestaciones Tempranas de Riesgo Cardiovascular en Jóvenes y Adultos Colombianos), collected between 2014-2017, which aimed to assess changes in lifestyle and CVD during attendance at university (aged 18-30 years) [20]. Details of the study design, characteristics of participants and clinical assessments have been published elsewhere [23-25]. A total of 1838 collegiate students from three distinct areas of Colombia - the capital district of Bogota, Boyacá, and Santiago de Cali-were enrolled to participate in the study. Before the recruitment process, collegiate students attended an information meeting, where they were informed of the purpose and procedures of the study. The gender distribution was similar to that of the entire university population. The final sample included in this paper was 1467 (64.2\%, 942 women) participants with full valid data. All participants 
provided written consent, and each study was approved by the local authorized institutional review boards (Bogotá UMB Code Nº1-1802-2013, UR Code N ${ }^{\circ}$ CEI-ABN026-000010; Cali UNIAJC Code $\mathrm{N}^{\circ}$ 111-02.01.48/16; Tunja Code $\mathrm{N}^{\circ}$ RECT 60) and complied with the Declaration of Helsinki (World Medical Association for Human Subjects). The students who agreed to participate and who had signed the informed consent form were given appointments for the following procedures.

\subsection{Anthropometric and Body Composition}

After completing another general information questionnaire, participants were instructed to wear light clothing (for example, a t-shirt and shorts) for the physical exam. Once the subjects were barefoot and in their underwear, their body weight $(\mathrm{kg})$ was measured using an electric scale (Model Tanita ${ }^{\circledR}$ BC-420-MA ${ }^{\circledR}$ Tokyo, Japan) with a range of 0 to $200 \mathrm{~kg}$ and with an accuracy of within $100 \mathrm{~g}$. Height was measured with a portable stadiometer with a precision of $0.1 \mathrm{~mm}$ and a range of $0-2.50 \mathrm{~m}$ (Seca ${ }^{\circledR}$ 213, Hamburg, Germany). Body mass index (BMI) was calculated by using the formula proposed by Quetelet, where BMI = body mass $(\mathrm{kg}) /$ height $\left(\mathrm{m}^{2}\right)$. Body mass index status was evaluated according to the World Health Organization criteria (World Health Organization, 2000) criteria (normal: 18.5 to $24.9 \mathrm{~kg} / \mathrm{m}^{2}$; overweight: 25.0 to $29.9 \mathrm{~kg} / \mathrm{m}^{2}$; and obese: $\geq 30 \mathrm{~kg} / \mathrm{m}^{2}$ ) [26]. Waist circumference (WC) was determined by the average of two measurements taken with tape (Lufkin W606PM ${ }^{\circledR}$, Parsippany, NJ, USA) at the waist (at the midpoint between the last rib and the iliac crest). The morphological evaluation process was carried out by a team of professionals (4 physical therapy professors) with extensive experience in anthropometric measurement. Anthropometric variables were measured in accordance with the International Society for the Advancement of Kinanthropometry (ISAK) guidelines [27]. Two percent of the sample was measured twice in order to ensure quality of measures. The technical error of measurement values were less than $2 \%$ for all anthropometric variables.

Body fat percentage $(\mathrm{BF} \%)$, visceral fat level, skeletal muscle mass $(\mathrm{kg})$ and fat mass $(\mathrm{kg})$, were determined for bioelectrical impedance analysis (BIA) by a tetrapolar whole body impedance (Model Tanita ${ }^{\circledR}$ BC-420-MA ${ }^{\circledR}$ Tokyo, Japan). This single-frequency foot-to-foot BIA device provides estimated values for $\mathrm{BF} \%$ by subtracting the weight of fat-free mass from the total body water. The impedance between the two feet was measured while an alternating current $(50 \mathrm{kHz}$ and $\sim 200 \mu \mathrm{A}$ ) passed through the lower body [28]. BIA has been reported to be a valid and reliable method of estimating body composition [29]. For the calculation of intra-inter-observer technical error of measurement, at least 50 subjects needed to be measured, and 48 adults participated (54\% women). The corresponding intra-observer technical error (\% reliability) of the measurements was 95\%. A detailed description of the BIA technique can be found elsewhere [30]. Then, the fat mass index (FMI) was calculated by dividing each subject's fat mass $(\mathrm{kg})$ by the square of his/her height (m), as previously described [31].

Grip strength as a "proxy" measure for muscle fitness and physical health was assessed using an adjustable digital handgrip dynamometer TKK-18 digital Grip-D dynamometer (Takey ${ }^{\circledR}$, Tokyo, Japan) (range: $5-100 \mathrm{~kg}$; precision: $0.1 \mathrm{~kg}$ ). It was performed to measure the participant's maximum force of handgrip. The grip span of the dynamometer was adjusted to the hand size of the participant. With the elbow in full extension, the participant had to press the dynamometer with the right hand for at least $2 \mathrm{~s}$. The test was then repeated with the left hand, performed twice, and the maximum score for each hand was recorded in kilograms. The average of the maximum scores for both hands was used in analyses. As there is substantial covariance between strength capacity and body mass, and the link between strength and both physical function and chronic health is directly mediated by the proportion of strength relative to body mass, handgrip strength was normalized as grip strength (NGS) per body mass; i.e., (handgrip strength in $\mathrm{kg}$ )/(body mass in $\mathrm{kg}$ ). The reproducibility of our data was $\mathrm{R}=0.96$. Intra-rater reliability was assessed by determining the intraclass correlation coefficient $(0.98$, CI 95\% 0.97-0.99, $n=20$, median age $=22.8 \pm 1.4$ years, $\left.66.2 \pm 5.4 \mathrm{~kg}, 1.67 \pm 0.1 \mathrm{~m}, 24.9 \pm 3.1 \mathrm{~kg} / \mathrm{m}^{2}\right)$. 


\subsection{Ideal CVH Behaviors}

Data on smoking were collected via self-reported questionnaires (number of cigarettes smoked per day). Ideal smoking status was determined as non-smoker or quit smoking $\geq 12$ months. A standardized questionnaire, the "FANTASTIC" lifestyle (family, physical activity (PA), nutrition, tobacco toxins, alcohol, sleep/stress, personality type, insight, career) questionnaire, was used to collect comprehensive information about substance use via a personal interview with participants [32]. The physically active category was defined as $\geq 150 \mathrm{~min}$ per week of physical activity. Alcohol consumption was defined as subjects who had consumed any alcoholic beverage $\geq 1$ times/week.

A seven-day recall was the dietary assessment tool used to complete the MetDiet adherence survey. The total score was divided into two categories of Mediterranean diet quality: $(1) \leq 7$ points = poor diet quality; and $\geq 8$ points = good diet quality (optimal Mediterranean diet style). Participants who had at least $\geq 8$ points were categorized as having an ideal healthy diet, whereas collegiate students with 7 points were classified as having a non-ideal healthy diet.

\subsection{Ideal CVH Risk Factors}

For blood measurements, the participants were asked to arrive in a fasting state, abstain from exercise training, caffeine, nicotine, and alcohol $12 \mathrm{~h}$ before the clinical examination, and continue their regular medication routines. Capillary blood samples $(40 \mu \mathrm{L})$ were collected to determine serum biochemical parameters, including fasting glucose and total cholesterol using portable Cardiocheck ${ }^{\circledR}$ equipment (Mexglobal SA, Parsippany, NJ, USA).

Blood pressure was taken with an automatic monitor (Omrom ${ }^{\circ H E M} 705$ CP/Omron M6 Comfort (Omron ${ }^{\circledR H e a l t h c a r e ~ E u r o p e ~ B . V ., ~ H o o f d d o r p, ~ t h e ~ N e t h e r l a n d s) ~ f o l l o w i n g ~ t h e ~ r e c o m m e n d a t i o n s ~ o f ~ t h e ~}$ European Heart Society (on the right arm, with participants in a supine position and after $10 \mathrm{~min}$ of rest) (ESH/ESC Task Force for the Management of Arterial Hypertension, 2013). During the measurement, the participants were seated with their arm supported at the level of the heart.

\subsection{AHA Criteria}

The AHA guidelines [10] were used to construct an ideal CVH index based on the 7-metrics using the cut-off points for adults, with the participants receiving one point for the presence of each ideal metric. The ideal behaviors defined by the AHA were as follows: BMI $<25 \mathrm{~kg} / \mathrm{m}^{2}$, physical active individuals (participants who exercised $\geq 150 \mathrm{~min}$ of moderate activity per week), non-smoking status (either never having smoked or having quit smoking $>12$ months ago), and consumption of a dietary pattern that promotes ideal $\mathrm{CVH}$. Some modifications of the AHA recommendations were required to evaluate diet. Participants who had at least $\geq 8$ points in the MetDiet questionnaire were categorized as having an ideal healthy diet, whereas collegiate students with 7 points were classified as having a non-ideal healthy diet. The clinical and laboratory parameters were classified as an untreated systolic blood pressure $<120 \mathrm{mmHg}$ and diastolic blood pressure $<80 \mathrm{mmHg}$, untreated total cholesterol $\leq 200 \mathrm{mg} / \mathrm{dL}$, and untreated fasting blood glucose $<100 \mathrm{mg} / \mathrm{dL}$.

Finally, the participants were categorized into 1 of 3 health levels based on the number of $\mathrm{CVH}$ metrics in the ideal range that they exhibited: the healthiest level (favorable ideal CVH score) was defined as having between 5 and 7 metrics in the ideal range; the intermediate level, 3 to 4 metrics; and the unfavorable level, 0 to 2 metrics. These cut-off points have been used in prior international studies [33].

\subsection{Diagnoses of Metabolic Syndrome}

Participants were considered to have a diagnosis of MetS if they had three or more of the following: (1) abdominal obesity (WC $\geq 80 \mathrm{~cm}$ in females and $\geq 90 \mathrm{~cm}$ in males); (2) hypertriglyceridemia ( $\geq 150 \mathrm{~g} / \mathrm{dL})$; (3) low high density lipoprotein cholesterol, HDL-c $(<50 \mathrm{mg} / \mathrm{dL}$ in females and $<40 \mathrm{mg} / \mathrm{dL}$ in males); (4) high blood pressure (systolic blood pressure $\geq 130 \mathrm{mmHg}$ or diastolic 
blood pressure $\geq 85 \mathrm{mmHg}$ ); (5) high fasting glucose ( $\geq 100 \mathrm{mg} / \mathrm{dL}$ ). MetS was defined in accordance with the updated harmonized criteria of the IDF [34].

\subsection{Statistical Analysis}

Descriptive characteristics are provided as means, $95 \%$ confidence Interval (CI), and percentages. Both statistical (Kolmogorov-Smirnov test) and graphical methods (normal probability plots) were used to examine the fit to a normal distribution for each continuous variable. The categorical variables were compared using the Chi squared test. To assess the relationship between muscular fitness and visceral fat ratio and the number of $\mathrm{CVH}$ metric, MetS and cardiometabolic risk factors, all study subjects were divided according to quartiles of the MVF ratio (first quartile (Q1 lowest group), second quartile (Q2), third quartile (Q3) and fourth quartile (Q4 highest group). The association between MVF and ideal CVH metrics, as well as with ideal CVH behaviors and factors separately, was assessed by ANCOVA. Finally, logistic regression (odds ratio (OR)) models were employed to compare the prevalence of medium-high MVF (i.e., 3-4th quartiles) across a number of ideal CVH metrics (poor (0-2 metrics), intermediate (3-4 metrics) and ideal (5-7 metrics)) after adjusting by age, gender, university and alcohol use. $\mathrm{CVH}$ metrics were also examined as a continuous variable, considering the OR per a 1-metric-higher overall profile. Thus, association between MVF across ideal CVH behaviors (smoking, body mass index, physical activity, and Mediterranean diet adherence), ideal CVH factors (total cholesterol, blood pressure, and plasma glucose) and 7-metric cardiovascular health in college students were analyzed after adjusted by age, gender, university and alcohol use. Statistical analyses were performed using SPSS-IBM (Software, v.24.0 SPSS Inc., Chicago, IL, USA). A $p$ value of $<0.05$ was defined as statistically significant.

\section{Results}

As shown in Table 1, comparisons between Q1, Q2, Q3, and Q4 show that when compared to the other three quartiles, Q4 had a higher prevalence of physical activity, body mass index (BMI) $<25 \mathrm{~kg} / \mathrm{m}^{2}$, a healthy diet, and fasting glucose $<100 \mathrm{mg} / \mathrm{dL}$. The proportions of subjects with MetS were $32.3 \%$ in Q1, 5.0\% in Q2, 1.9\% in Q3, and 2.2\% in Q4, which were strongly negatively correlated with the MFV ratios in the respective quartiles.

There was an increasing trend of body weight, WC, and BMI from Q1 to Q4 ( $p$ for trend $<0.001$ ). Skeletal muscle mass was significantly lower in Q1 than in Q3, while fat mass, fat mass index, body fat, and visceral fat level were significantly higher in Q1 than in Q2, Q3, or Q4 ( $p$ for trend $<0.001$ ). The muscle fitness (handgrip and NGS) of the subjects in Q4 was significantly greater than that of the subjects in Q1 to Q2 ( $p$ for trend $<0.001$ ).

Figure 1 shows the prevalence of each ideal CVH metric according to the MVF ratio quartiles. The category containing $5-7$ metrics was $11.1 \%$ in Q1, $52.0 \%$ in Q2, $64.2 \%$ in Q3, and $65.1 \%$ in Q4. In addition, the proportions of subjects with 3-4 metrics were $70.5 \%$ in Q1, $45.8 \%$ in Q2, 34.8\% in Q3, and $34.6 \%$ in Q4. Finally, the category containing $0-2$ metrics was $18.4 \%$ in Q1, 2.2\% in Q2, $1.0 \%$ in $\mathrm{Q} 3$, and $0.3 \%$ in $\mathrm{Q} 4$. Each of these indicators of improved cardiovascular health was worse where there was a lower MVF ratio (Figure 2). The logistic regression analysis showed that subjects with a medium-high MVF ratio (i.e., 3-4th quartiles) had an OR of 2.103 of ideal CVH metrics after adjusting for age, gender, university, and alcohol intake (95\% CI 1.832 to $2.414 ; p<0.001)$. 
Table 1. The prevalence rates of the number of cardiovascular health $(\mathrm{CVH})$ metrics, metabolic syndrome (MetS), anthropometric characteristics, blood pressure, and muscular fitness parameters for 1467 study subjects with quartile stratification according to the muscle fitness to visceral fat (MVF) ratio.

\begin{tabular}{|c|c|c|c|c|c|c|c|}
\hline Characteristics & $\begin{array}{c}\text { 1st Quartile } \\
(n=366)\end{array}$ & $\begin{array}{c}\text { 2nd Quartile } \\
\quad(n=368)\end{array}$ & $\begin{array}{c}\text { 3rd Quartile } \\
(n=366)\end{array}$ & $\begin{array}{c}\text { 4th Quartile } \\
(n=367)\end{array}$ & \multicolumn{3}{|c|}{$\begin{array}{c}p \text { Value } \\
\text { Chi-Square Test }\end{array}$} \\
\hline \multicolumn{8}{|l|}{ Goal/Metric } \\
\hline Not currently smoking (\%) & 71.4 & 74.9 & 68.9 & 70.4 & & 0.431 & \\
\hline $\mathrm{BMI}<25 \mathrm{~kg} / \mathrm{m}^{2}(\%)$ & 11.5 & 75.5 & 99.5 & 100.0 & & $<0.0001$ & \\
\hline Physically active (\%) & 19.1 & 33.2 & 24.1 & 39.2 & & $<0.0001$ & \\
\hline Healthy $\operatorname{diet}(\%)$ & 12.4 & 12.5 & 10.8 & 14.5 & & 0.473 & \\
\hline Total cholesterol < $200 \mathrm{mg} / \mathrm{dL}(\%)$ & 93.4 & 95.6 & 95.9 & 96.2 & & 0.088 & \\
\hline Fasting glucose $<100 \mathrm{mg} / \mathrm{dL}(\%)$ & 86.6 & 91.5 & 90.7 & 91.8 & & 0.034 & \\
\hline \multirow[t]{3}{*}{ Metabolic syndrome prevalence } & 32.3 & 5.0 & 1.9 & 2.2 & & $<0.0001$ & \\
\hline & \multirow{2}{*}{$\begin{array}{c}\text { 1st Quartile } \\
(n=366)\end{array}$} & \multirow{2}{*}{$\begin{array}{c}\text { 2nd Quartile } \\
\quad(n=368)\end{array}$} & \multirow{2}{*}{$\begin{array}{c}\text { 3rd Quartile } \\
\quad(n=366)\end{array}$} & \multirow{2}{*}{$\begin{array}{c}\text { 4th Quartile } \\
(n=367)\end{array}$} & \multicolumn{3}{|c|}{ ANCOVA * } \\
\hline & & & & & Q1 vs. Q2 & Q1 vs. Q3 & Q1 vs. Q4 \\
\hline \multicolumn{8}{|l|}{ Anthropometric } \\
\hline Age (years) & $21.5(21.2-21.8)$ & $21.0(20.8-21.4)$ & $20.0(19.7-20.3)$ & $19.8(19.6-20.1)$ & - & - & - \\
\hline Weight $(\mathrm{kg})$ & $77.2(76.2-78.1)$ & $64.4(63.5-65.4)$ & $56.6(55.6-57.5)$ & $54.7(53.8-55.6)$ & $<0.0001$ & $<0.0001$ & $<0.0001$ \\
\hline Height (m) & $1.65(1.65-1.66)$ & $1.64(1.64-1.65)$ & $1.63(1.63-1.64)$ & $1.64(1.64-1.65)$ & 0.211 & 0.010 & 0.178 \\
\hline $\mathrm{WC}(\mathrm{cm})$ & $85.1(84.4-85.9)$ & $75.3(74.6-76.0)$ & $69.4(68.8-70.2)$ & $67.4(66.8-68.1)$ & $<0.0001$ & $<0.0001$ & $<0.0001$ \\
\hline $\operatorname{BMI}\left(\mathrm{kg} / \mathrm{m}^{2}\right)$ & $28.1(27.8-28.4)$ & $23.8(23.5-24.1)$ & $20.9(20.6-21.2)$ & $20.3(20.1-20.6)$ & $<0.0001$ & $<0.0001$ & $<0.0001$ \\
\hline Fat mass $(\mathrm{kg})$ & $23.9(23.4-24.4)$ & $14.8(14.4-15.4)$ & $9.6(9.1-10.1)$ & $8.8(8.4-9.4)$ & $<0.0001$ & $<0.0001$ & $<0.0001$ \\
\hline Fat mass index $\left(\mathrm{kg} / \mathrm{m}^{2}\right)$ & $8.7(8.6-9.0)$ & $5.5(5.4-5.8)$ & $3.5(3.4-3.8)$ & $3.4(3.3-3.6)$ & $<0.0001$ & $<0.0001$ & $<0.0001$ \\
\hline Skeletal muscle mass (kg) & $50.7(50.3-51.3)$ & $47.0(46.6-47.6)$ & $44.6(44.1-45.1)$ & $43.4(43.0-43.9)$ & $<0.0001$ & $<0.0001$ & $<0.0001$ \\
\hline Body fat $(\%)$ & $30.8(30.3-31.3)$ & $23.3(22.9-23.9)$ & $17.4(16.9-17.9)$ & $16.2(15.8-16.7)$ & $<0.0001$ & $<0.0001$ & $<0.0001$ \\
\hline Visceral fat level & $5.6(5.4-5.8)$ & $2.2(2.1-2.4)$ & $1.2(1.1-1.4)$ & $0.8(0.7-1.0)$ & $<0.0001$ & $<0.0001$ & $<0.0001$ \\
\hline MVF ratio & $0.08(0.07-0.09)$ & $0.22(0.21-0.22)$ & $0.43(0.42-0.44)$ & $0.60(0.59-0.61)$ & $<0.0001$ & $<0.0001$ & $<0.0001$ \\
\hline \multicolumn{8}{|l|}{ Blood pressure } \\
\hline Systolic blood pressure (mmHg) & $120.1(118.8-121.5)$ & $116.6(115.4-118.0)$ & $112.4(111.1-113.8)$ & $111.9(110.7-113.2)$ & 0.001 & $<0.0001$ & $<0.0001$ \\
\hline Diastolic blood pressure(mmHg) & $76.1(74.8-77.3)$ & $74.6(73.5-75.9)$ & $71.4(70.3-72.6)$ & $71.2(70.1-72.3)$ & 0.374 & $<0.0001$ & $<0.0001$ \\
\hline \multicolumn{8}{|l|}{ Muscular fitness } \\
\hline Handgrip (kg) & $30.9(30.3-31.6)$ & $30.8(30.2-31.5)$ & $27.7(27.0-28.4)$ & $32.3(31.6-32.9)$ & 1.000 & $<0.0001$ & 0.033 \\
\hline NGS & $0.40(0.39-0.41)$ & $0.47(0.46-0.48)$ & $0.48(0.47-0.49)$ & $0.58(0.58-0.59)$ & $<0.0001$ & $<0.0001$ & $<0.0001$ \\
\hline
\end{tabular}

Values are presented as the mean (95\% CI). The MVF ratio was divided into quartiles with the following (min-max) values: Q1: 0.015-0.136, Q2: 0.137-0.338, Q3: 0.339-0.498 and Q4: 0.499-0.904. * To compare between groups, all dependent variables were analyzed by using ANCOVA with adjustment by age, gender, university and alcohol use as covariates. Categorical variables were analyzed by using the Chi-square test. WC, waist circumference; BMI, body mass index; MVF ratio, muscular fitness to visceral fat level ratio; NGS, normalized grip strength (Handgrip $(\mathrm{kg}) /$ body mass $(\mathrm{kg})$ ). 


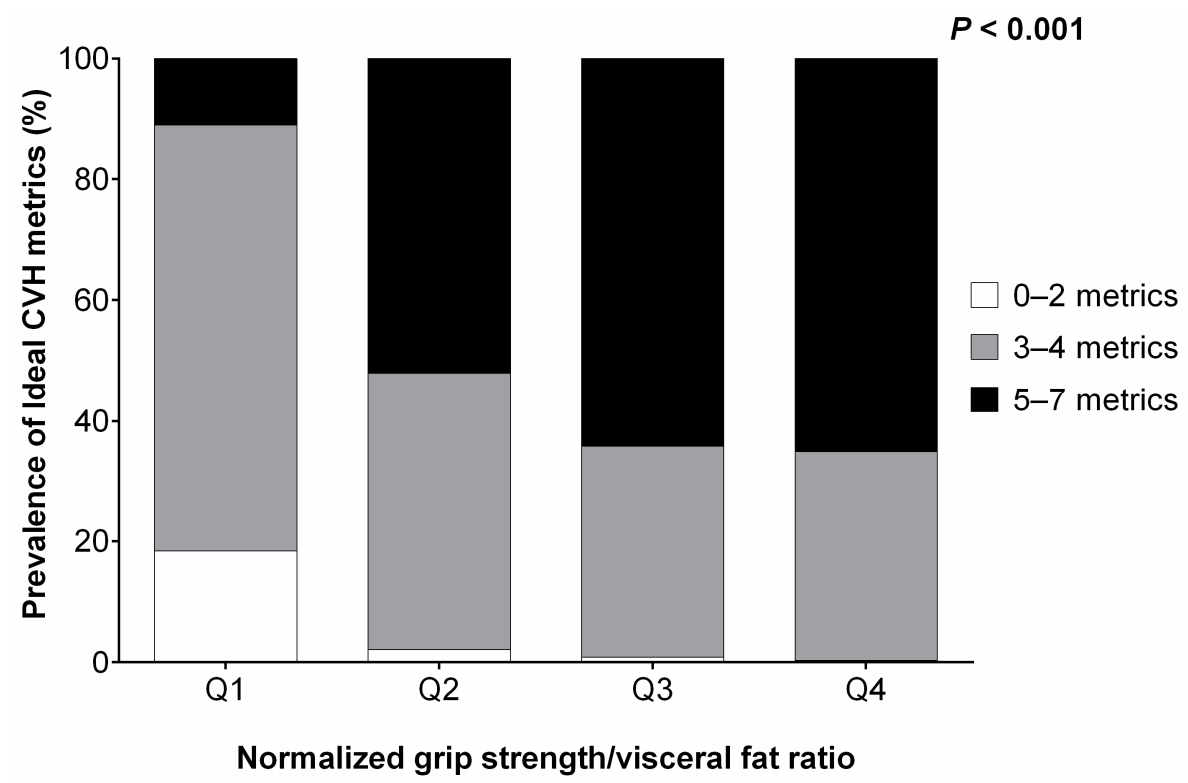

Figure 1. The comparisons of the number of $\mathrm{CVH}$ metrics in study subjects with quartile stratification according to the MVF ratio.
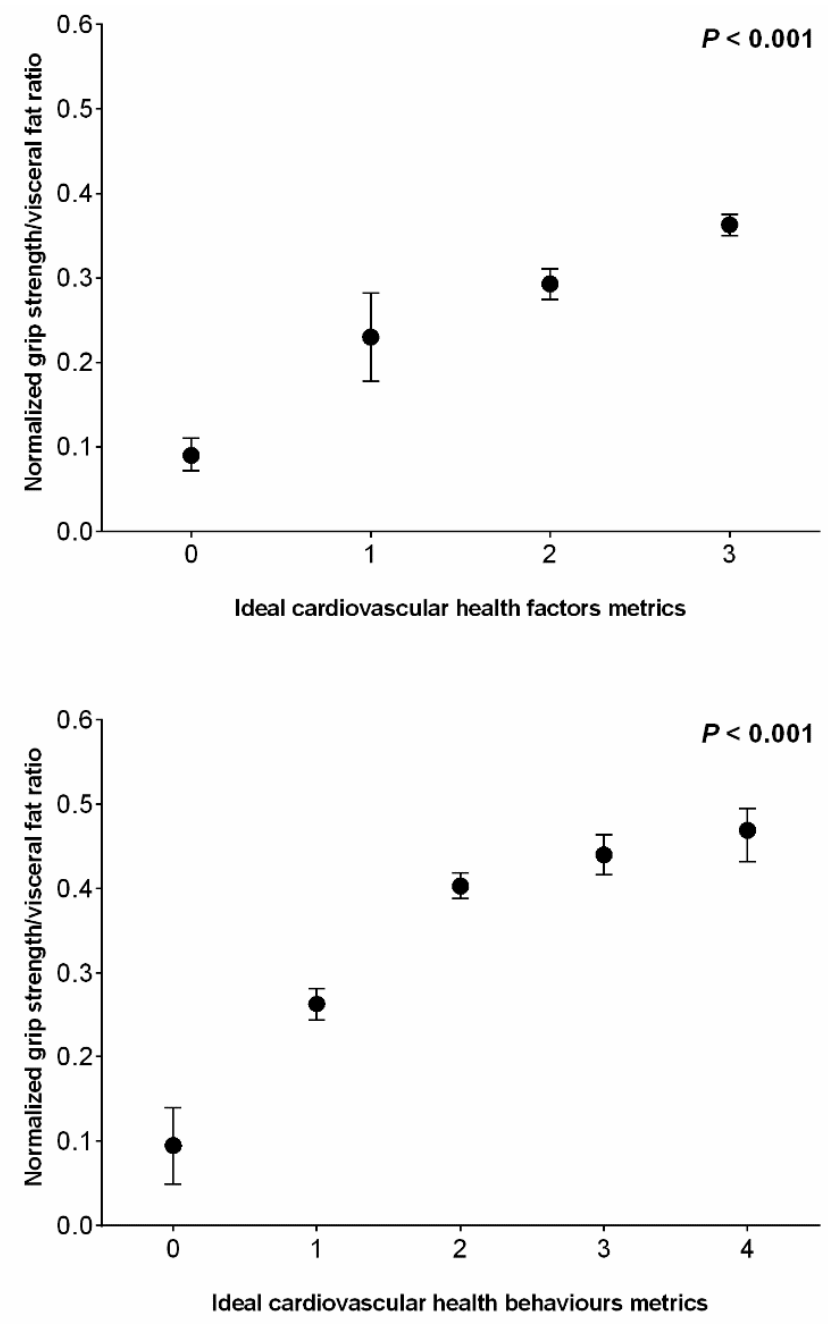

Figure 2. Cont. 


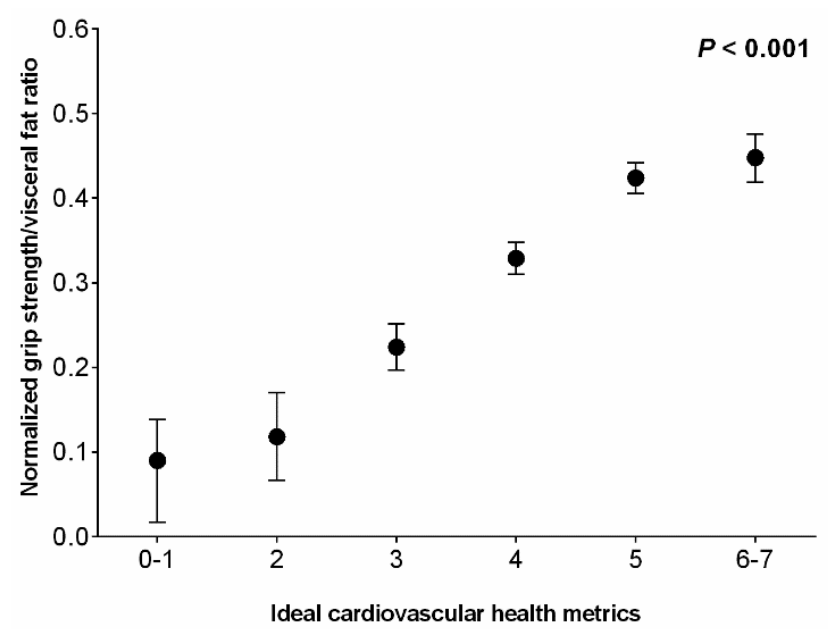

Figure 2. Association between muscular fitness (NGS) to visceral fat ratio across ideal CVH behaviors (smoking, body mass index, cardiorespiratory fitness, and Mediterranean diet adherence), ideal CVH factors (total cholesterol, blood pressure, and plasma glucose) and 7-metrics cardiovascular health in college students.

\section{Discussion}

The aim of this study was to investigate the relationship between MVF ratio and the prevalence of MetS and $\mathrm{CVH}$ metrics in a large population of 1467 Colombian young adults. The findings indicate that those subjects positioned in $\mathrm{Q} 4$ present better $\mathrm{CVH}$ metrics, they show a greater proportion of normal BMI values, are more active, and have a healthier diet, as well as having total cholesterol and glucose levels within the normal range. Consistent with these results, the participants in Q3 to $\mathrm{Q} 4$ showed the lowest prevalence of metabolic syndrome (1.9 to $2.2 \%$ ). In contrast, those subjects who were stratified into Q1 presented, in general, a higher number of altered $\mathrm{CVH}$ metrics, together with a higher prevalence of MetS (32.3\%). Several studies have shown that subjects who exhibit greater numbers of these healthy lifestyle components (HLCs) are more likely to reach later adulthood with lower blood pressure, cholesterol, and blood glucose levels, and favorable intermediate CVD markers [35-37].

Muscle fitness and visceral adipose tissue have been independently associated with cardiometabolic health; however, to the best of our knowledge, the association between MVF ratio and $\mathrm{CVH}$ has not been examined previously. Our results show that each of the indicators of improved cardiovascular health are worse with a decreased MVF ratio. Overall, these findings support the hypothesis that the MVF ratio could be used as a complementary assessment measure that could help clinicians identify young adults with a low CVH score. In addition, adopting a lifestyle that does not result in a decreased MVF ratio is important in order to prevent unfavorable CVH levels and a higher prevalence of MetS in early adulthood. In this sense, our findings indicate that the MVF ratio is a relevant and effective indicator for defining $\mathrm{CVH}$ metrics in Colombian young adults. Therefore, these findings add to the literature supporting the importance of healthy lifestyles for maintaining $\mathrm{CVH}$ [38], and reducing atherosclerosis [37], CVD events [39], and mortality [40,41].

On the other hand, the relationship between muscle fitness and the prevention of chronic disease in adult populations is widely recognized [42-44]. Evidence suggests that muscle mass and muscular fitness decrease progressively after the age of 20 [45]. Therefore, early adulthood seems to be a crucial timeframe for monitoring and intervention. Muscle fitness has been recognized as a predicting factor for cardiometabolic diseases [46]. Indeed, Steene-Johannessen et al. [47], in a study of 2818 adolescents from Norway, concluded that there is an inverse association between muscle fitness and cardiometabolic profile and MetS risk.

In addition, growing scientific evidence suggests that visceral adipose tissue linked to insulin resistance may play a relevant role in the development of cardiometabolic risk and MetS [48-54]. In line 
with this, Cho et al. [49], concluded that the highest quartiles with regard to visceral adipose tissue exhibit a higher risk of MetS as compared with the lower quartiles. Therefore, the visceral fat ratio is an essential tool for estimating cardiometabolic risk and identifying young adults with low CVH.

To the best of our knowledge, our study is the first to apply the CVH metrics to a population of young adults from Colombia, a country with significant health inequality and which is in a situation of nutritional transition. In this context, applying the 7 AHA cardiovascular health metrics allows us to find out how these measures are useful for assessing risks at the populational level in Colombia. In clinical practice, the results from the AHA measures could be used to help assess baseline cardiovascular health in Colombian young people and identify areas where interventions should focus, especially with regard to policies and environmental changes.

Certain limitations of this study also should be addressed. First, the cross-sectional design does not allow us to explain causality. Thus, future prospective analysis is necessary to determine any relationship between the MVF ratio and CVH. In addition, the gold standard for the assessment of visceral fat is magnetic resonance imaging (MRI) and computed tomography (CT). However, in this study, visceral fat measurement was assessed by BIA, which, although it is a highly reliable device, provided an indirect measure. Finally, a potential limitation of our study is that we were not able to adjust for unmeasured variables such as eating time interval and frequency that could affect cardiovascular health, muscle fitness and visceral fat deposition [55]. Despite these limitations, the major strength of the study is that the data were collected from a community-based cohort of young adults in Colombia. Furthermore, highly standardized procedures were developed within the FUPRECOL study to avoid measurement bias.

\section{Conclusions}

A lower MVF ratio is associated with worse CVH metrics and a higher prevalence of MetS in early adulthood. Therefore, MVF ratio is an important and efficient indicator for defining ideal $\mathrm{CVH}$ in young adults. Consequently, we propose the use of the MVF ratio as a complementary assessment measure that may be useful for clinicians. Taking into account the fact that CVD and MetS in young adults are considered important public health problems, this study is especially relevant since it provides a novel tool for the early identification of these health issues.

Author Contributions: Conceptualization, R.R.-V. and M.I.; Data curation, R.R.-V. and M.I.; Formal analysis, R.R.-V., J.S.-R. and E.G.-J.; Funding acquisition, R.R.-V.; Investigation, R.R.-V., J.S.-R. and E.G.-J.; Methodology, R.R.-V. and M.C.-R.; Project administration, R.R.-V.; Resources, R.R.-V.; Supervision, M.C.-R.; Validation, M.I.; Writing-original draft, M.C.-R. and E.G.-J.; Writing—review \& editing, M.C.-R. and J.S.-R.

Funding: This study was part of the project entitled "Body Adiposity Index and Biomarkers of Endothelial and Cardiovascular Health in Adults", which was funded by Centre for Studies on Measurement of Physical Activity, School of Medicine and Health Sciences, Universidad del Rosario (Code $\mathrm{N}^{\circ}$ FIUR DN-BG001), Institución Universitaria Antonio José Camacho (Code N 111-02.01.48/16), Universidad Santo Tomás (Code N²013004), Universidad Manuela Beltrán (Code N FT201204), and Universidad de Boyacá (Code $\mathrm{N}^{\circ}$ RECT 60). M.I, is granted in part by a research grant PI17/01814 of the Ministerio de Economía, Industria y Competitividad (ISCIII, FEDER). The funder had no role in the study design, data collection, data analysis and interpretation, preparation of the manuscript, or decision to publish.

Acknowledgments: The authors gratefully acknowledge the contributions of Carolina Sandoval-Cuellar, Elisa Andrea Cobo, Monica Liliana Ojeda, Aura Cristina Quino-Ávila, Daniel Prieto, Jorge E. Correa-Bautista, Andres Vivas, Katherine Gonzalez-Ruiz, Jeison Sepulveda, Claudia Maritza Rubio-Barreto, Rocío del Pilar Castellanos-Vega, Florencio Arias-Coronel and Hugo Alejandro Carrillo who assisted the authors with obtaining data. We also acknowledge Hector ReinaldoTriana-Reina, USTA University, for assistance with data analysis.

Conflicts of Interest: The authors declare no conflict of interest.

\section{References}

1. Roth, G.A.; Forouzanfar, M.H.; Moran, A.E.; Barber, R.; Nguyen, G.; Feigin, V.L.; Naghavi, M.; Mensah, G.A.; Murray, C.J.L. Demographic and Epidemiologic Drivers of Global Cardiovascular Mortality. N. Engl. J. Med. 2015, 372, 1333-1341. [CrossRef] [PubMed] 
2. González, S.A.; Castiblanco, M.A.; Arias-Gómez, L.F.; Martinez-Ospina, A.; Cohen, D.D.; Holguin, G.A.; Almanza, A.; Lemos, D.M.C.; Correa-Bautista, J.E.; Escobar, I.D.; et al. Results From Colombia's 2016 Report Card on Physical Activity for Children and Youth. J. Phys. Act. Health 2016, 13, S129-S136. [CrossRef] [PubMed]

3. Fortich, R.; Gutierrez, J.D.; Fortich, R.; Gutierrez, J.D. Los Determinantes de la Obesidad en Colombia. Rev. Econ. Reg. 2011, 5, 155-182.

4. Collins, K.M.; Dantico, M.; Shearer, N.B.C.; Mossman, K.L. Heart disease awareness among college students. J. Community Health 2004, 29, 405-420. [CrossRef] [PubMed]

5. Burke, J.D.; Reilly, R.A.; Morrell, J.S.; Lofgren, I.E. The University of New Hampshire's Young Adult Health Risk Screening Initiative. J. Am. Diet. Assoc. 2009, 109, 1751-1758. [CrossRef] [PubMed]

6. Martínez-Torres, J.; Correa-Bautista, J.; González-Ruíz, K.; Vivas, A.; Triana-Reina, H.; Prieto-Benavidez, D.; Carrillo, H.; Ramos-Sepúlveda, J.; Villa-González, E.; García-Hermoso, A.; et al. A Cross-Sectional Study of the Prevalence of Metabolic Syndrome and Associated Factors in Colombian Collegiate Students: The FUPRECOL-Adults Study. Int. J. Environ. Res. Public Health 2017, 14, 233. [CrossRef] [PubMed]

7. Morrell, J.S.; Lofgren, I.E.; Burke, J.D.; Reilly, R.A. Metabolic Syndrome, Obesity, and Related Risk Factors Among College Men and Women. J. Am. Coll. Health 2012, 60, 82-89. [CrossRef]

8. Iacobellis, G. Local and systemic effects of the multifaceted epicardial adipose tissue depot. Nat. Rev. Endocrinol. 2015, 11, 363-371. [CrossRef]

9. Stampfer, M.J.; Hu, F.B.; Manson, J.E.; Rimm, E.B.; Willett, W.C. Primary Prevention of Coronary Heart Disease in Women through Diet and Lifestyle. N. Engl. J. Med. 2000, 343, 16-22. [CrossRef]

10. Lloyd-Jones, D.M.; Hong, Y.; Labarthe, D.; Mozaffarian, D.; Appel, L.J.; Van Horn, L.; Greenlund, K.; Daniels, S.; Nichol, G.; Tomaselli, G.F.; et al. American Heart Association Strategic Planning Task Force and Statistics Committee Defining and Setting National Goals for Cardiovascular Health Promotion and Disease Reduction: The American Heart Association's Strategic Impact Goal Through 2020 and Beyond. Circulation 2010, 121, 586-613. [CrossRef]

11. Oikonen, M.; Laitinen, T.T.; Magnussen, C.G.; Steinberger, J.; Sinaiko, A.R.; Dwyer, T.; Venn, A.; Smith, K.J.; Hutri-Kahonen, N.; Pahkala, K.; et al. Ideal Cardiovascular Health in Young Adult Populations from the United States, Finland, and Australia and Its Association With cIMT: The International Childhood Cardiovascular Cohort Consortium. J. Am. Heart Assoc. 2013, 2, e000244. [CrossRef] [PubMed]

12. Desai, C.S.; Ning, H.; Liu, K.; Reis, J.P.; Gidding, S.S.; Armstrong, A.; Lima, J.A.C.; Lloyd-Jones, D.M. Cardiovascular Health in Young Adulthood and Association with Left Ventricular Structure and Function Later in Life: The Coronary Artery Risk Development in Young Adults Study. J. Am. Soc. Echocardiogr. 2015, 28, 1452-1461. [CrossRef] [PubMed]

13. Hruskova, J.; Maugeri, A.; Podroužková, H.; Štípalová, T.; Jakubík, J.; Barchitta, M.; Medina-Inojosa, J.; Homolka, M.; Agodi, A.; Kunzova, S.; et al. Association of Cardiovascular Health with Epicardial Adipose Tissue and Intima Media Thickness: The Kardiovize Study. J. Clin. Med. 2018, 7, 113. [CrossRef] [PubMed]

14. Roshanravan, B.; Patel, K.V.; Fried, L.F.; Robinson-Cohen, C.; de Boer, I.H.; Harris, T.; Murphy, R.A.; Satterfield, S.; Goodpaster, B.H.; Shlipak, M.; et al. Health ABC study Association of Muscle Endurance, Fatigability, and Strength With Functional Limitation and Mortality in the Health Aging and Body Composition Study. J. Gerontol. Ser. A Biol. Sci. Med. Sci. 2017, 72, 284-291. [CrossRef] [PubMed]

15. Kamada, M.; Shiroma, E.J.; Buring, J.E.; Miyachi, M.; Lee, I. Strength Training and All-Cause, Cardiovascular Disease, and Cancer Mortality in Older Women: A Cohort Study. J. Am. Heart Assoc. 2017, 6, e007677. [CrossRef] [PubMed]

16. García-Hermoso, A.; Carrillo, H.A.; González-Ruíz, K.; Vivas, A.; Triana-Reina, H.R.; Martínez-Torres, J.; Prieto-Benavidez, D.H.; Correa-Bautista, J.E.; Ramos-Sepúlveda, J.A.; Villa-González, E.; et al. Fatness mediates the influence of muscular fitness on metabolic syndrome in Colombian collegiate students. PLOS ONE 2017, 12, e0173932. [CrossRef] [PubMed]

17. Fraser, B.J.; Huynh, Q.L.; Schmidt, M.D.; Dwyer, T.; Venn, A.J.; Magnussen, C.G. Childhood Muscular Fitness Phenotypes and Adult Metabolic Syndrome. Med. Sci. Sport Exerc. 2016, 48, 1715-1722. [CrossRef]

18. Mišigoj-Duraković, M.; Sorić, M.; Matika, D.; Jukić, I.; Duraković, Z. Which is more important for reducing the odds of metabolic syndrome in men: Cardiorespiratory or muscular fitness? Obesity 2016, 24, $238-244$. [CrossRef] 
19. Camargo-Ramos, C.; Correa-Bautista, J.; Correa-Rodríguez, M.; Ramírez-Vélez, R. Dietary Inflammatory Index and Cardiometabolic Risk Parameters in Overweight and Sedentary Subjects. Int. J. Environ. Res. Public Health 2017, 14, 1104. [CrossRef]

20. Ramírez-Vélez, R.; García-Hermoso, A.; Agostinis-Sobrinho, C.; Mota, J.; Santos, R.; Correa-Bautista, J.; Peña-Guzmán, C.; Domínguez-Sánchez, M.; Schmidt-RioValle, J.; González-Jiménez, E. Pubertal Stage, Body Mass Index, and Cardiometabolic Risk in Children and Adolescents in Bogotá, Colombia: The Cross-Sectional Fuprecol Study. Nutrients 2017, 9, 644. [CrossRef]

21. Herrán, O.F.; Patiño, G.A.; Del Castillo, S.E. Dietary transition and excess weight in adults according to the Encuesta de la Situación Nutricional en Colombia, 2010. Biomedica 2016, 36, 109-120. [PubMed]

22. Lee, S.; Kuk, J.L.; Kim, Y.; Arslanian, S.A. Measurement site of visceral adipose tissue and prediction of metabolic syndrome in youth. Pediatr. Diabetes 2011, 12, 250-257. [CrossRef] [PubMed]

23. Correa-Rodríguez, M.; Ramírez-Vélez, R.; Correa-Bautista, J.; Castellanos-Vega, R.; Arias-Coronel, F.; González-Ruíz, K.; Alejandro Carrillo, H.; Schmidt-RioValle, J.; González-Jiménez, E. Association of Muscular Fitness and Body Fatness with Cardiometabolic Risk Factors: The FUPRECOL Study. Nutrients 2018, 10, 1742. [CrossRef] [PubMed]

24. Garcia-Hermoso, A.; Tordecilla-Sanders, A.; Correa-Bautista, J.E.; Peterson, M.D.; Izquierdo, M.; Quino-Ávila, A.C.; Sandoval-Cuellar, C.; González-Ruíz, K.; Ramírez-Vélez, R. Muscle strength cut-offs for the detection of metabolic syndrome in a nonrepresentative sample of collegiate students from Colombia. J. Sport Health Sci. 2018. [CrossRef]

25. Agostinis-Sobrinho, C.; Santos, R.; Rosário, R.; Moreira, C.; Lopes, L.; Mota, J.; Martinkenas, A.; García-Hermoso, A.; Correa-Bautista, J.; Ramírez-Vélez, R.; et al. Optimal Adherence to a Mediterranean Diet May Not Overcome the Deleterious Effects of Low Physical Fitness on Cardiovascular Disease Risk in Adolescents: A Cross-Sectional Pooled Analysis. Nutrients 2018, 10, 815. [CrossRef] [PubMed]

26. WHO. Obesity: Preventing and Managing the Global Epidemic; World Health Organization: Geneva, Switzerland, 2000.

27. Marfell-Jones, M.; Olds, T.; Stewart, A. International Standards for Anthropometric Assessment; ISAK: Potchefstroom, South Africa, 2011; ISBN 0620362073.

28. Bousbiat, S.; Jaffrin, M.Y.; Dongmo, E. Comparison of body fat-free masses calculated from hand-to-foot and foot-to-foot resistances with DXA measurements. Med. Biol. Eng. Comput. 2011, 49, 1329-1336. [CrossRef] [PubMed]

29. Lee, S.Y.; Gallagher, D. Assessment methods in human body composition. Curr. Opin. Clin. Nutr. Metab. Care 2008, 11, 566-572. [CrossRef] [PubMed]

30. Ramírez-Vélez, R.; Correa-Bautista, J.; Martínez-Torres, J.; González-Ruíz, K.; González-Jiménez, E.; Schmidt-RioValle, J.; Garcia-Hermoso, A. Performance of Two Bioelectrical Impedance Analyses in the Diagnosis of Overweight and Obesity in Children and Adolescents: The FUPRECOL Study. Nutrients 2016, 8, 575. [CrossRef] [PubMed]

31. Liu, P.; Ma, F.; Lou, H.; Liu, Y. The utility of fat mass index vs. body mass index and percentage of body fat in the screening of metabolic syndrome. BMC Public Health 2013, 13, 629. [CrossRef] [PubMed]

32. Ramírez-Vélez, R.; Agredo, R.A. The Fantastic instrument's validity and reliability for measuring Colombian adults' life-style. Rev. Salud Publica 2012, 14, 226-237. [CrossRef] [PubMed]

33. García-Hermoso, A.; Hackney, A.C.; Ramírez-Vélez, R. Ideal cardiovascular health predicts lower risk of abnormal liver enzymes levels in the Chilean National Health Survey (2009-2010). PLoS ONE 2017, 12, e0185908. [CrossRef] [PubMed]

34. Alberti, K.G.M.M.; Eckel, R.H.; Grundy, S.M.; Zimmet, P.Z.; Cleeman, J.I.; Donato, K.A.; Fruchart, J.-C.; James, W.P.T.; Loria, C.M.; Smith, S.C.; et al. Harmonizing the Metabolic Syndrome: A Joint Interim Statement of the International Diabetes Federation Task Force on Epidemiology and Prevention; National Heart, Lung, and Blood Institute; American Heart Association; World Heart Federation; International Atherosclerosis Society; and International Association for the Study of Obesity. Circulation 2009, 120, 1640-1645. [CrossRef] [PubMed]

35. Gall, S.L.; Jamrozik, K.; Blizzard, L.; Dwyer, T.; Venn, A. Healthy lifestyles and cardiovascular risk profiles in young Australian adults: The Childhood Determinants of Adult Health Study. Eur. J. Cardiovasc. Prev. Rehabil. 2009, 16, 684-689. [CrossRef] [PubMed] 
36. Liu, K.; Daviglus, M.L.; Loria, C.M.; Colangelo, L.A.; Spring, B.; Moller, A.C.; Lloyd-Jones, D.M. Healthy lifestyle through young adulthood and the presence of low cardiovascular disease risk profile in middle age: The Coronary Artery Risk Development in (Young) Adults (CARDIA) study. Circulation 2012, 125, 996-1004. [CrossRef] [PubMed]

37. Spring, B.; Moller, A.C.; Colangelo, L.A.; Siddique, J.; Roehrig, M.; Daviglus, M.L.; Polak, J.F.; Reis, J.P.; Sidney, S.; Liu, K. Healthy lifestyle change and subclinical atherosclerosis in young adults: Coronary Artery Risk Development in Young Adults (CARDIA) study. Circulation 2014, 130, 10-17. [CrossRef] [PubMed]

38. Gooding, H.C.; Shay, C.M.; Ning, H.; Gillman, M.W.; Chiuve, S.E.; Reis, J.P.; Allen, N.B.; Lloyd-Jones, D.M. Optimal Lifestyle Components in Young Adulthood Are Associated with Maintaining the Ideal Cardiovascular Health Profile into Middle Age. J. Am. Heart Assoc. 2015, 4, e002048. [CrossRef] [PubMed]

39. Chiuve, S.E.; Fung, T.T.; Rexrode, K.M.; Spiegelman, D.; Manson, J.E.; Stampfer, M.J.; Albert, C.M. Adherence to a low-risk, healthy lifestyle and risk of sudden cardiac death among women. JAMA 2011, 306, 62-69. [CrossRef] [PubMed]

40. Nechuta, S.J.; Shu, X.-O.; Li, H.-L.; Yang, G.; Xiang, Y.-B.; Cai, H.; Chow, W.-H.; Ji, B.; Zhang, X.; Wen, W.; et al. Combined Impact of Lifestyle-Related Factors on Total and Cause-Specific Mortality among Chinese Women: Prospective Cohort Study. PLoS Med. 2010, 7, e1000339. [CrossRef]

41. Mitchell, J.A.; Bornstein, D.B.; Sui, X.; Hooker, S.P.; Church, T.S.; Lee, C.D.; Lee, D.; Blair, S.N. The Impact of Combined Health Factors on Cardiovascular Disease Mortality. Am. Heart J. 2010, 160, 102. [CrossRef]

42. Jurca, R.; Lamonte, M.J.; Church, T.S.; Earnest, C.P.; Fitzgerald, S.J.; Barlow, C.E.; Jordan, A.N.; Kampert, J.B.; Blair, S.N. Associations of muscle strength and aerobic fitness with metabolic syndrome in men. Med. Sci. Sports Exerc. 2004, 36, 1301-1307. [CrossRef]

43. Zheng, Y.; Manson, J.E.; Yuan, C.; Liang, M.H.; Grodstein, F.; Stampfer, M.J.; Willett, W.C.; Hu, F.B. Associations of Weight Gain From Early to Middle Adulthood With Major Health Outcomes Later in Life. JAMA 2017, 318, 255. [CrossRef] [PubMed]

44. López-Martínez, S.; Sánchez-López, M.; Solera-Martinez, M.; Arias-Palencia, N.; Fuentes-Chacón, R.M.; Martínez-Vizcaíno, V. Physical activity, fitness, and metabolic syndrome in young adults. Int. J. Sport Nutr. Exerc. Metab. 2013, 23, 312-321. [CrossRef] [PubMed]

45. Gallagher, D.; Visser, M.; De Meersman, R.E.; Sepúlveda, D.; Baumgartner, R.N.; Pierson, R.N.; Harris, T.; Heymsfield, S.B. Appendicular skeletal muscle mass: Effects of age, gender, and ethnicity. J. Appl. Physiol. 1997, 83, 229-239. [CrossRef] [PubMed]

46. García-Hermoso, A.; Cavero-Redondo, I.; Ramírez-Vélez, R.; Ruiz, J.; Ortega, F.B.; Lee, D.-C.; Martínez-Vizcaíno, V. Muscular strength as a predictor of all-cause mortality in apparently healthy population: A systematic review and meta-analysis of data from approximately 2 million men and women. Arch. Phys. Med Rehabil. 2018. [CrossRef] [PubMed]

47. Steene-Johannessen, J.; Anderssen, S.A.; Kolle, E.; Andersen, L.B. Low muscle fitness is associated with metabolic risk in youth. Med. Sci. Sports Exerc. 2009, 41, 1361-1367. [CrossRef] [PubMed]

48. Yumi, M.; Toru, N.; Shuichiro, Y.; Yoshihiko, T.; Tetsuji, Y.; Tetsuya, M.; Mitsuhiko, N. Visceral fat area cutoff for the detection of multiple risk factors of metabolic syndrome in Japanese: The hitachi health study. Obesity 2012, 20, 1744-1749. [CrossRef] [PubMed]

49. Cho, S.A.; Joo, H.J.; Cho, J.Y.; Lee, S.H.; Park, J.H.; Hong, S.J.; Yu, C.W.; Lim, D.S. Visceral fat area and serum adiponectin level predict the development of metabolic syndrome in a community-based asymptomatic population. PLoS ONE 2017, 12, e0169289. [CrossRef] [PubMed]

50. Matsushita, Y.; Nakagawa, T.; Yamamoto, S.; Takahashi, Y.; Yokoyama, T.; Mizoue, T.; Noda, M. Effect of longitudinal changes in visceral fat area on incidence of metabolic risk factors: The hitachi health study. Obesity 2013, 21, 2126-2129. [CrossRef]

51. Shah, R.V.; Murthy, V.L.; Abbasi, S.A.; Blankstein, R.; Kwong, R.Y.; Goldfine, A.B.; Jerosch-Herold, M.; Lima, J.A.C.; Ding, J.; Allison, M.A. Visceral Adiposity and the Risk of Metabolic Syndrome Across Body Mass Index. JACC Cardiovasc. Imaging 2014, 7, 1221-1235. [CrossRef]

52. Xia, M.F.; Chen, Y.; Lin, H.D.; Ma, H.; Li, X.M.; Aleteng, Q.; Li, Q.; Wang, D.; Hu, Y.; Pan, B.S.; Li, X.J.; Li, X.Y.; Gao, X. A indicator of visceral adipose dysfunction to evaluate metabolic health in adult Chinese. Sci. Rep. 2016, 1, 38214. [CrossRef] 
53. Druet, C.; Baltakse, V.; Chevenne, D.; Dorgeret, S.; Zaccaria, I.; Wang, Y.; Levy-Marchal, C. Independent effect of visceral adipose tissue on metabolic syndrome in obese adolescents. Horm. Res. 2008, 70, 22-28. [CrossRef] [PubMed]

54. Pouliot, M.C.; Després, J.P.; Nadeau, A.; Moorjani, S.; Prud'Homme, D.; Lupien, P.J.; Tremblay, A.; Bouchard, C. Visceral obesity in men. Associations with glucose tolerance, plasma insulin, and lipoprotein levels. Diabetes 1992, 41, 826-834. [CrossRef] [PubMed]

55. Maugeri, A.; Kunzova, S.; Medina-Inojosa, J.R.; Agodi, A.; Barchitta, M.; Homolka, M.; Kiacova, N.; Bauerova, H.; Sochor, O.; Lopez-Jimenez, F.; et al. Association between eating time interval and frequency with ideal cardiovascular health: Results from a random sample Czech urban population. Nutr. Metab. Cardiovasc. Dis. 2018, 28, 847-855. [CrossRef] [PubMed]

(C) 2018 by the authors. Licensee MDPI, Basel, Switzerland. This article is an open access article distributed under the terms and conditions of the Creative Commons Attribution (CC BY) license (http:/ / creativecommons.org/licenses/by/4.0/). 